\title{
Agôn
}

Revue des arts de la scène

Critiques | Saison 2012-2013

\section{Testament - She She Pop et leurs pères}

$\mathrm{Tu}$ aimeras ton père

\section{Marion Siéfert}

\section{(2) OpenEdition}

\section{Journals}

Édition électronique

URL : http://journals.openedition.org/agon/2335

DOI : 10.4000/agon.2335

ISSN : 1961-8581

Éditeur

Association Agôn

Référence électronique

Marion Siéfert, "Testament - She She Pop et leurs pères », Agôn [En ligne], Critiques, mis en ligne le 03 décembre 2012, consulté le 23 septembre 2020. URL : http://journals.openedition.org/agon/2335 ;

DOI : https://doi.org/10.4000/agon.2335

Ce document a été généré automatiquement le 23 septembre 2020

Association Agôn et les auteurs des articles 


\section{Testament - She She Pop et leurs pères}

Tu aimeras ton père

Marion Siéfert

\section{RÉFÉRENCE}

Testament, invité au Festival d'Automne à Paris, du 28 novembre au 3 décembre 2012 au Théâtre des Abbesses.

$1 \quad$ Le Roi Lear de Shakespeare est une pièce d'amour et de pouvoir. Ou plutôt elle parle d'un père qui se démet de tous ses pouvoirs, en échange de l'amour et des soins que ses filles promettent de lui apporter. Si l'une, Cordelia la plus sincère, n'a rien à dire de l'amour qu'elle porte à son père, les deux autres s'engagent tête baissée dans la bataille : qui aimera le plus, obtiendra le plus. Comment juger dès lors un amour qui se monnaye en biens matériels? Faut-il condamner les filles de Lear, ces «mauvaises héritières " ? Peut-on hériter tout en conservant une attitude critique et révoltée face à la classe dominante? Et n'en fait-on désormais pas partie? La grande force des membres de She She Pop (Sebastian Bark, Fanni Halmburger, Lisa Lucassen, Mieke Matzke, Illia Papatheodorou et Berit Stumpf) est de ne pas condamner d'emblée ces filles égoïstes dans lesquelles elles ne se retrouvent que trop bien et de prendre au sérieux ce conflit de générations. N'occultons pas ce marchandage d'amour en le déclarant immoral. Le montrer au théâtre, c'est ne pas rester coincé dans les atermoiements familiaux et faire de ce conflit un événement social. 
Testament, de She She Pop

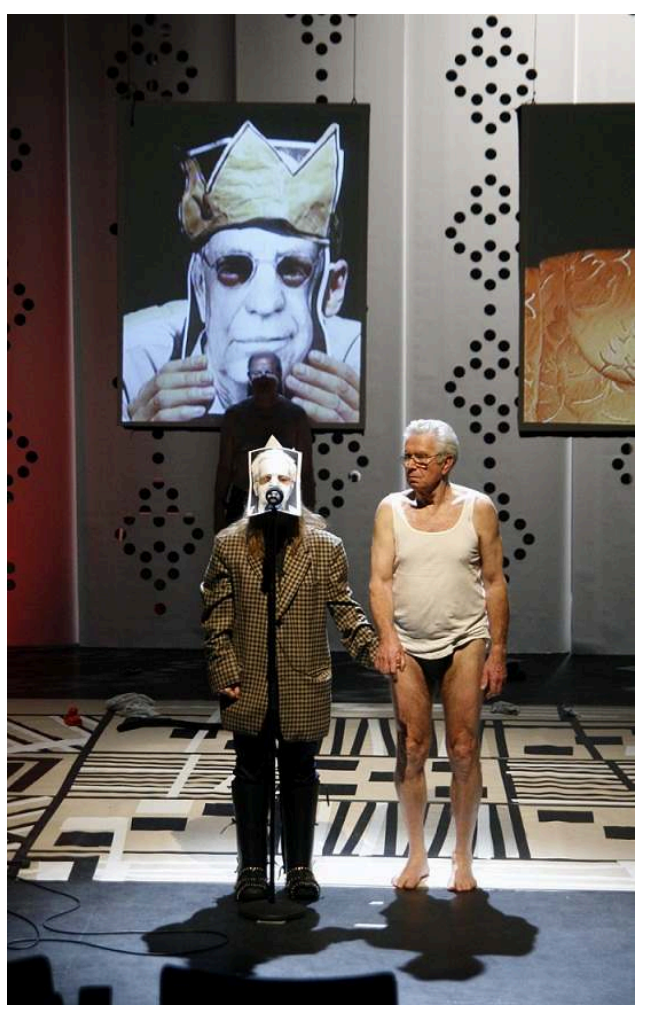

(C) Doro Tuch

2 D'ordinaire allergique aux textes dramatiques, She She Pop a choisi pour une fois de s'attaquer à un canon de la littérature, Le Roi Lear: une façon de montrer avec encore plus de clarté la portée universelle de leur théâtre qui se nourrit avant tout de ce qu'elles sont, de ce qu'elles vivent et des sociétés dans lesquelles elles évoluent. Avec Testament, ce sont leurs véritables pères qu'elles amènent sur scène, afin de " préparer » la phase difficile et délicate de leur vieillissement et de leur déchéance et d'aborder certains détails épineux. Shakespeare avec son radicalisme tragique s'avère alors être le dramaturge parfait: en suivant la fable, elles sont certaines de traiter chaque question sans fausse pudeur et de mettre le doigt là où le bât blesse. Ainsi, puisque l'amour filial, chez Shakespeare, se monnaye, les quatre membres de She She Pop présents sur le plateau expliquent d'abord au public - avant que les pères ne rentrent en scène - comment on doit être pour plaire à leurs paternels et donc, gagner leurs faveurs. Puis arrive le moment des réclamations (sous la forme d'une liste délibérément matérialiste) et des calculs : par exemple, Mieke Matzke, sans enfants, réclame une part d'héritage supplémentaire, compensant l'amour du père pour les enfants de son frère, amour, déclare-t-elle, qui s'est détourné d'elle et dont elle n'a pas profité. Ensuite, lorsque les pères s'installent chez leurs filles, ils sont contraints de reconnaître que tout ne se passe pas comme ils l'avaient imaginé et que les plus faibles, dans l'histoire, ce sont bien eux. Tandis que les enfants s'installent sans ménagement dans les fauteuils confortables de leurs papas et qu'ainsi le "changement de génération " se réalise, les pères s'acheminent dans un long processus de décrépitude vers la mort. Seuls quelques soins gériatriques effectués avec dégoût retardent la fermeture du couvercle du cercueil. À la fin, pas de réconciliation, mais une litanie de pardons qui ressemble à un chapelet de reproches réciproques. 
3 Mais pourquoi parler de choses si intimes en public? She Pop Pop ne réalise pas une adaptation de Shakespeare, mais pose la question de la société, du regard des autres, de structures de pouvoir et du monnayage de l'amour, choses sommes toutes extrêmement fréquentes au théâtre. Car dans ce collectif, rien ne se fait sur scène sans le public, sans que son rôle ait été défini, délimité et réfléchi. Si She She Pop se reconnaît dans ses mauvaises héritières, c'est bien parce qu'elles ont, elles aussi, l'habitude de réfléchir sur le rapport économique qui relie spectateurs et performers et de se considérer comme des prestataires de service. Dans une de leurs premières productions, Negamorphosen, la poursuite du spectacle était suspendue à un investissement financier des spectateurs; dans Bad, elles reprenaient le pacte sadomasochiste pour entrâner la salle au bout du plaisir et de la douleur; dans Träumlabor, elles se proposaient de réaliser les fantaisies, rêves, cauchemars et lubies du public. Testament reprend la structure fondamentalement sociale et publique du Roi Lear. Avant le premier acte, un pacte est passé avec les spectateurs : on nous signifie que nous allons jouer le rôle de la Cour du Roi Lear qui assiste à sa déchéance. Un micro placé sur le devant de la scène permet aux performers de parler directement au public et de lui offrir une entrée dans le spectacle. C'est par sa seule présence, que l'action sur scène est rendue possible. Au fil de la représentation, alors que certains moments des répétitions avec les pères sont restitués sur scène, que le processus d'élaboration du spectacle est sans cesse réfléchi, on comprend que c'est cette alternance, ce jeu entre réalité et fiction, rôle et auto-représentation, intimité et espace social, qui rend possible d'aborder cette question avec autant de radicalité, de distance et d'humour à la fois. Rarement on aura joué aussi honnêtement. 